\title{
Effects of Diets with Different Proportions of Protein/ Carbohydrate on Retinal Manifestations in $d b$ Mice
}

\author{
EMI ARIMURA ${ }^{1,2}$, HIDEAKI OKATANI $^{3}$, TOMOAKI ARAKI $^{3}$, MIHARU USHIKAI $^{2}$, MIWA NAKAKUMA $^{1,2}$, \\ MASAHARU ABE ${ }^{2}$, HIROAKI KAWAGUCHI ${ }^{2}$, HIROYUKI IZUMI ${ }^{3}$ and MASAHISA HORIUCHI ${ }^{2}$ \\ ${ }^{1}$ Department of Life and Environmental Science, Kagoshima Prefectural College, Kagoshima, Japan; \\ ${ }^{2}$ Department of Hygiene and Health Promotion Medicine, \\ Graduate School of Medical and Dental Sciences, Kagoshima University, Kagoshima, Japan; \\ ${ }^{3}$ Drug Safety Research Laboratories, Shin Nippon Biomedical Laboratories, Ltd., Kagoshima, Japan
}

\begin{abstract}
Background/Aim: Diabetic nephropathy is aggravated by a higher intake of total protein. The effects of diets with different proportions of protein and carbohydrate on diabetic retinopathy in db mice, a type-2 diabetes animal model, were examined, as well as diabetic nephropathy. Materials and Methods: Control and db mice at 5 weeks of age were fed the diets (\% energy of protein/carbohydrate/fat; L-diet: 12/71/17; H-diet: 24/59/17) under ad libitum conditions and pair-feeding conditions for 6 weeks, respectively. Results: Mice fed the H-diet showed significantly greater retinal thickness by optical coherence tomography, and lower mRNA levels of angiotensinogen. Comparing combinations of diets and genotypes, $\mathrm{db}-\mathrm{H}$ mice showed significantly higher mRNA levels of angiotensinconverting enzyme, advanced glycosylation end productspecific receptor, and cluster of differentiation molecule $11 \mathrm{~b}$ (a microglial marker) than db-L mice. Conclusion: Dietary protein and carbohydrate proportions influenced retinal manifestations, including retinal thickness and gene expression in control and diabetic mice.
\end{abstract}

Diabetic retinopathy is one of the three major complications of diabetes, and it is the leading cause of visual impairment and blindness among adults (1). A recent epidemiological study found diabetic retinopathy prevalence to be $34.6 \%$ for individuals with diabetes (2). In the Wisconsin

This article is freely accessible online.

Correspondence to: Masahisa Horiuchi, Department of Hygiene and Health Promotion Medicine, Graduate School of Medical and Dental Sciences, Kagoshima University, 8-35-1 Sakuragaoka, Kagoshima 890-8544, Japan. Tel: +81 9922755289, Fax: +81 992658434, e-mail: masakun@m.kufm.kagoshima-u.ac.jp

Key Words: $d b$ Mice, renin-angiotensin system, optical coherence tomography, diabetic retinopathy.
Epidemiological Study of Diabetic Retinopathy, microalbuminuria, representing nephropathy, was associated with the presence of retinopathy in individuals with diabetes (3). The recent rise in the numbers of diabetes and diabetic retinopathy cases worldwide is likely to be related to lifestyle/life environment rather than genetic factors, as a global genetic diversity has not changed appreciably over this short period of time (4-7). Lifestyle factors, including nutrition, have been altered markedly in recent decades $(8$, 9). Diabetic nephropathy is aggravated by higher intake of total protein $(10,11)$. However, the impact of altered nutrition, especially protein content, on the development of diabetic retinopathy is not fully understood $(10,11,12)$.

Glycemic control and blood pressure control reduce the progression of diabetic retinopathy, and ophthalmological treatment including laser applications plays a prominent role in the control of diabetic retinopathy. However, currently there are no drugs that inhibit the onset or progression of diabetic retinopathy, except for inhibitors of the renin-angiotensin (RA) system (13-17). Regarding nutritional intervention, patients with diabetic retinopathy have been managed by a low-energy diet of suppressed carbohydrate intake and relatively highprotein intake, but the influence of diet on the pathophysiology of retinopathy is not fully understood. A rodent study of diabetic nephropathy reported an additive effect of RA system inhibitors and a low-protein diet on kidney manifestations (18). A low-protein diet may have additional beneficial effects through suppressed expression of genes involved in the kidney RA system. The effect of dietary protein content diets (12-24\% energy), which is the range in regular human diets $(4,8)$, on glucose levels and renal manifestations in $d b$ mice $(19,20)$, an animal model for diabetes with leptin-receptor deficiency. In the experiments using $d b$ mice, a high-protein, low-carbohydrate diet increased blood glucose levels and exacerbated renal manifestations, compared with a low-protein, high-carbohydrate diet $(21,22)$. The dietary protein content should be examined for its 
influences on the retina as well as the kidney, because of the beneficial effects of RA system inhibitors on nephropathy and retinopathy caused by diabetes. A cross-sectional observation revealed that diabetic patients with retinopathy showed higher intake of protein than diabetic patients without retinopathy (23). However, this finding remains to be confirmed because only a monovariate statistical procedure was performed without consideration of confounding factors.

In the present study, we evaluated the impacts of dietary protein content on retinal manifestations in $d b$ mice, an animal model representing retinal neurodegenerative changes in the early period of diabetes (24). We examined morphological changes using optical coherence tomography, and alteration of expression of neuronal and glial marker genes and of genes involved in the RA system.

\section{Materials and Methods}

Animals. Male diabetic mice [C57BLKS(BKS). Cg-+ Lepr ${ }^{d b} /+$ $L e p r d b / \mathbf{J} ; d b$, diabetic], having a homozygous mutation of the leptin receptor, and control mice (BKS.Cg-Dock $7^{\mathrm{m}}+/$ Dock $7 \mathrm{~m}+/ \mathrm{J}$; CT, control) at 4 weeks of age were obtained from Charles River Japan (Kanagawa, Japan) (24-26). The mice were housed individually in a humidity and temperature-controlled facility $\left(50 \pm 20 \%, 22 \pm 3^{\circ} \mathrm{C}\right)$ under a $12 \mathrm{~h}$ light/dark cycle (light from 0700-1900) in the animal facility of Shin Nippon Biomedical Laboratories, Ltd. All mice had ad libitum access to water, and CT mice had ad libitum access to food. $d b$ mice were subject to pair-feeding conditions during the experimental period.

Experimental design. Twelve CT and $12 d b$ mice purchased at 4 weeks of age were used. Under ad libitum conditions, the CT mice were acclimatized to their surroundings for one week. They were then randomly separated into two groups $(\mathrm{N}=6)$, each supplied with a different diet for 6 weeks. The diets were as follows: $12 \%$ energy from protein (L-diet; low-protein, high-carbohydrate: $12 \%$ protein, $71 \%$ carbohydrate, $17 \%$ fat), and $24 \%$ energy from protein (H-diet; high-protein, low-carbohydrate: $24 \%$ protein, $59 \%$ carbohydrate, $17 \%$ fat). The protein sources of the two diets were composed of $50 \%$ animal and $50 \%$ plant protein (Table I). Under pair-feeding conditions, $d b$ mice were supplied with the same amount of H-diet $(d b-\mathrm{H})$ as the amount of L-diet consumed by $d b$-L mice, resulting in the consumption of similar fat content. The body weight (BW) and intake of food and water were measured every week during morning and afternoon periods, respectively. We measured food and water intake by subtracting the remaining quantities from the amounts supplied (weight). On the last day of the experiments, the mice were anesthetized by pentobarbital $(32.4 \mathrm{mg} / \mathrm{kg})$ and then as much blood as possible was collected from the heart using a syringe containing EDTA-2K (10 $\mu \mathrm{l}$ of $200 \mathrm{mM})$. The blood was centrifuged, and then the supernatant was stored at $-80^{\circ} \mathrm{C}$. Tissues and organs, including, kidneys, liver, pancreas, and heart were removed, and then weighed. Retinas were dissected and immediately frozen in liquid nitrogen. All tissues were then stored at $-80^{\circ} \mathrm{C}$ until analysis.

Optical coherence tomography. We scanned the retinal layers with optical coherence tomography (Spectralis, Heidelberg Engineering GmbH, MA, USA) under non-anesthetized conditions with Mydrin$\mathrm{P}$ ophthalmic solution for mydriasis (tropicamide and phenylephrine;
Santen Pharmaceuticals, Osaka, Japan). We investigated retinal thickness by taking tomographic images of the ocular fundi. Total retinal thickness was measured in an area of $1.0 \mathrm{~mm}$ in diameter centered on the optic nerve head of mice at 11 weeks of age (24).

Biochemical measurements. Blood glucose (BG) and urinary glucose (UG) were measured using a commercial kit (glucose CIItest Wako; WAKO, Tokyo, Japan) according to the manufacturer's instructions. Urine was taken during the morning period. Urinary C-peptide and plasma insulin were measured using respective ELISA kits (Yanaihara Institute, Shizuoka, Japan; Morinaga Institute of Biological Science, Kanagawa, Japan). HbA1c was measured by an immunoassay (DCA 2000 system; Bayer Healthcare LLC, NJ, USA). Aldosterone was measured (Clinical Pathology Laboratory Co., Kagoshima, Japan).

Real-time PCR for quantification of $m R N A$. Frozen retinas were used for isolation of total RNA. Isolated RNA was treated with DNase to remove genomic contamination. First-strand cDNA synthesis was performed using $5 \mu \mathrm{g}$ total RNA with an oligo-(dT)20 primer following the manufacturer's instructions (Invitrogen, Carlsbad, CA, USA). Real-time quantitative PCR was performed using SYBRgreen on a TAKARA detection system (TAKARA, Shiga, Japan) under the conditions recommended by the manufacturer. The primer sequences were as follows (27-33): angiotensinogen (Agt, NM_007428), forward: 5'-GGC CGC CGA GAA GCT AGA-3' and reverse: 5'-GGC TGG CCG TGG GAT CTA-3'; renin (Renin, NM_031192), forward: 5'-GCC GCC TCT ACC TTG CTT GTG-3' and reverse: 5' GGG GCA GCT CGG TGA CCT CT-3'; angiotensin I converting enzyme (Ace, NM_207624), forward: 5'-AGG GAA CAT GTG GGC GCA GAC-3' and reverse: 5'-CGG TGG GCT TCT CTA ACA TCG A-3'; advanced glycosylation end product-specific receptor (Ager, NM_007425), forward: 5'-TGA GGA GAG GAA GGC CCC G-3' and reverse: 5'-GCC ATC ACA CAG GCT CGA TC-3'; neuronal nuclei (NeuN, NM_001039167), as a marker of neural cells, forward: 5'-GAG GAG TGG CCC GTT CTG-3' and reverse: 5'-AGG CGG AGG AGG GTACTG-3'; glial fibrillary acidic protein (Gfap, NM_010277) , as a marker of astrocytes, forward: 5'-GAA CAA CCT GGC TGC GTA TA-3' and reverse: 5'GCG ATT CAA CCT TTC TCT CC-3'; cluster of differentiation molecule 11b (CD11b, NM_001082960), as a marker of microglial cells, forward: 5'-GAT CAA CAA TGT GAC CGT ATG-3' and reverse: 5'-GAT CCC GGA AAT TGG AGT GAG-3'; glyceraldehyde 3-phosphate dehydrogenase (Gapdh, NM_008084), forward: 5'-CCG CAT CTT CTT GTG CAG TGC C-3' and reverse: 5'-GGG GTC GTT GAT GGC AAC AAT CTC-3'.

We measured mRNA levels of the genes involved in the development of diabetic retinopathy. The relative level of mRNA was calculated using cycle time $(\mathrm{Ct})$ values, which were normalized against the value of Gapdh. Relative quantification (fold change) between different samples was then determined according to the $2^{-\Delta \Delta \mathrm{Ct}}$ method. The level of mRNAs in CT-L mice was set at 1.00.

Data analysis. Values are shown as means \pm or + standard error (SE). Statistical analysis was performed using two-way (repeated measurement or factorial) analysis of variance (ANOVA) as appropriate (34). Significant differences were determined using the $t$-test (Ekuseru-Toukei 2010, Social Survey Research Information, Tokyo, Japan; SPSS Medical Model, ver. 24, International Business Machines Corporation, Tokyo, Japan). Differences with $p<0.05$ were considered significant. 
Table I. Composition of the diets used in the experiments.

A

\begin{tabular}{lcc}
\hline & \multicolumn{2}{c}{ Diets (g) } \\
\cline { 2 - 3 } & $\mathrm{L}$ & $\mathrm{H}$ \\
\hline Casein $^{1}$ & 6,4 & 12,8 \\
Soy protein $^{2}$ & 6,4 & 12,8 \\
$\alpha$ cornstarch $^{3}$ & 49,6 & 36,6 \\
$\beta$ cornstarch $^{4}$ & 14,5 & 14,5 \\
Sucrose $^{5}$ & 10 & 10 \\
Sucrose from MX and VX) $_{\text {Soybean oil }}$ & $(1.4)$ & $(1.4)$ \\
Supplements & 8,25 & 8,25 \\
$\quad$ L-cystine & & \\
DL-methionine $^{7}$ & 0,18 & 0,33 \\
Mineral mix $(\mathrm{MX})^{8}$ & 0,13 & 0,24 \\
${\text { Vitamin mix }(\mathrm{VX})^{8}}^{8}$ & 3,5 & 3,5 \\
Total* & 1 & 1 \\
\hline
\end{tabular}

B

\begin{tabular}{lcc}
\hline Proportion of energy & \multicolumn{2}{c}{ Diets (\% energy) } \\
\cline { 2 - 3 } & $\mathrm{L}$ & $\mathrm{H}$ \\
\hline Protein & 12 & 24 \\
Carbohydrates & 71 & 59 \\
Fat & 17 & 17 \\
Total & 100 & 100 \\
kcal/g & 4,29 & 4,29 \\
\hline
\end{tabular}

*Rounded off to the second decimal place. ${ }^{1}$ Acid casein (Meggle Japan Co., Ltd, Tokyo, Japan); ${ }^{2}$ Soy flour (Nisshin Oillio Group, Ltd, Tokyo, Japan); ${ }^{3}$ Nisshoku Alstar E (Nihon Shokuhin Kako Co., Ltd, Tokyo, Japan); ${ }^{4}$ Corn strach W (Shikishima Starch Mfg. Co., Ltd, Mie, Japan); ${ }^{5}$ Granulated sugar (Fuji Nihon Seito Co., Ltd, Tokyo, Japan); ${ }^{6}$ Daizu Hakko-yu (J-oil Mills Inc, Tokyo, Japan); ${ }^{7}$ Sigma-Aldrich, Japan, Co., Ltd, Tokyo, Japan; ${ }^{8}$ These mixtures were made of pure chemicals (Nosan Co., Ltd, Kanagawa, Japan).

\section{Results}

Food and water intake, body weight and organ weight. db$\mathrm{L}$ and $-\mathrm{H}$ mice showed significantly higher BW than CT-L and $-\mathrm{H}$ mice during the experiments, respectively. There was no significant difference in $\mathrm{BW}$ among $d b$ or CT mice fed the different diets (Figure 1A). Additionally, there was no significant difference in $\mathrm{BW}$ change during the experiments between $d b$ or CT mice fed the different diets ( $d b$-L: $10.9 \pm 2.0 \mathrm{~g}, d b-\mathrm{H}: 10.6 \pm 1.8 \mathrm{~g}, p=0.899$; CT-L: $7.0 \pm 0.6 \mathrm{~g}$, CT-H: $6.0 \pm 0.4 \mathrm{~g}, p=0.248)$. For water intake during the period, $d b$ - $\mathrm{L}$ and $-\mathrm{H}$ mice showed significantly higher intake compared with CT-L and -H mice, respectively. There was no significant difference in water intake among $d b$ or CT mice fed the different diets (Figure 1B). As shown in Figure
A

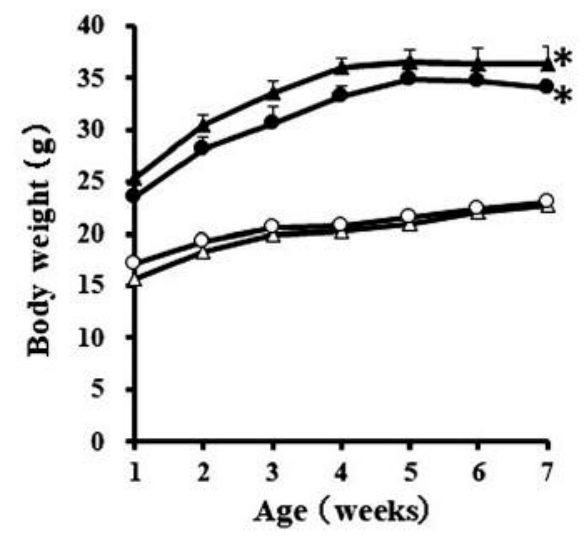

B

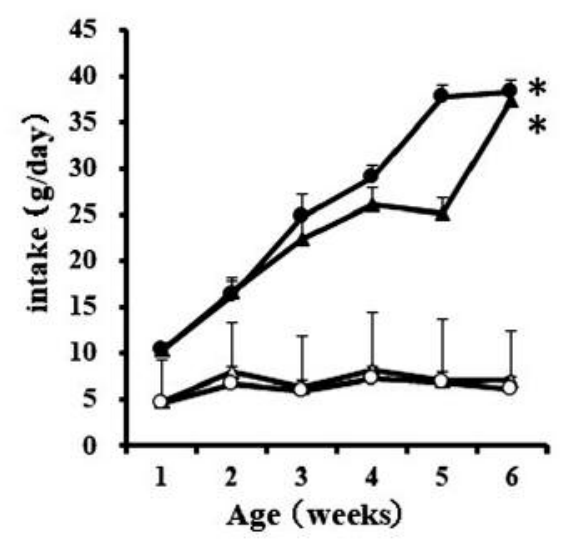

C

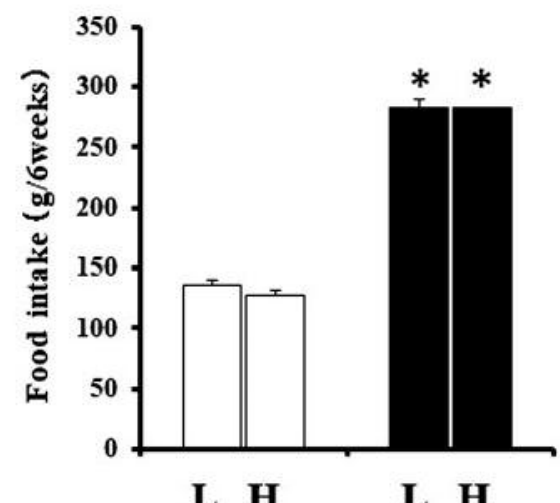

$\begin{array}{llll}\mathbf{H} & \mathbf{L} & \mathbf{H}\end{array}$

Figure 1. Change of body weight and water intake in control (CT) and db mice with different diet conditions. Body weight (A) and water intake (B) of $C T$ (open symbol) and $d b$ (closed symbol) mice fed with the different diets (low protein: triangle, high protein: circle) for 6 weeks. The total amounts of food eaten by CT (open symbol) and db (closed symbol) mice fed with a low protein diet $(L)$ or a high protein diet $(H)$ are shown in $(C)$. The data are presented as means $+S E$ from six $d b$ and six CT mice under the different diet conditions. Data were analyzed statistically by two-way ANOVA (repeated measurements) ( $A$ and $B$ ) or unpaired t-test $(C)$. ${ }^{*} p<0.05$ compared to $C T$ mice fed with the respective diet. 
Table II. Effect of diets on organ weights, blood and urinary parameters in CT and db mice.

\begin{tabular}{|c|c|c|c|c|c|c|c|}
\hline \multirow[b]{2}{*}{ Diet } & \multicolumn{2}{|c|}{ CT } & \multicolumn{2}{|c|}{$d b$} & \multicolumn{3}{|c|}{$p$-Value (two-way ANOVA) } \\
\hline & $\mathrm{L}$ & $\mathrm{H}$ & $\mathrm{L}$ & $\mathrm{H}$ & Diet & Genotype & Diet x Genotype \\
\hline $\mathrm{N}$ & 6 & 6 & 6 & 6 & & & \\
\hline \multicolumn{8}{|c|}{ Optical coherence tomography } \\
\hline Retinal thickness $(\mu \mathrm{m})$ & $178.8 \pm 9.6$ & $201.2 \pm 4.2$ & $184.2 \pm 6.9$ & $194.8 \pm 3.6$ & 0.020 & 0.94 & 0.381 \\
\hline \multicolumn{8}{|l|}{ Organ weight $(\mathrm{g})$} \\
\hline Kidney & $0.161 \pm 0.004$ & $0.180 \pm 0.004^{\# \#}$ & $0.208 \pm 0.004 * *$ & $0.233 \pm 0.010^{* * \#}$ & 0.001 & 0.000 & 0.570 \\
\hline Liver & $1.20 \pm 0.04$ & $1.31 \pm 0.01^{\#}$ & $2.53 \pm 0.08 * *$ & $1.99 \pm 0.14 * * \# \#$ & 0.017 & 0.000 & 0.001 \\
\hline Pancreas & $0.235 \pm 0.013$ & $0.291 \pm 0.006^{\# \#}$ & $0.239 \pm 0.005$ & $0.236 \pm 0.017 *$ & 0.030 & 0.038 & 0.018 \\
\hline Heart & $0.151 \pm 0.011$ & $0.147 \pm 0.006$ & $0.139 \pm 0.005$ & $0.138 \pm 0.003$ & 0.719 & 0.135 & 0.847 \\
\hline \multicolumn{8}{|l|}{ Blood parameters } \\
\hline HbAlc $(\%)$ & $3.65 \pm 0.10$ & $3.92 \pm 0.08$ & $>14.00$ & $>14.00$ & & & \\
\hline Glucose $(\mathrm{mg} / \mathrm{dl})$ & $217 \pm 8$ & $225 \pm 17$ & $999 \pm 100 * *$ & $923 \pm 126^{* *}$ & 0.681 & 0.000 & 0.609 \\
\hline Insulin $(\mathrm{ng} / \mathrm{ml})$ & $0.5 \pm 0.1$ & $0.5 \pm 0.1$ & $1.0 \pm 0.2$ & $1.8 \pm 0.2 * * \#$ & 0.027 & 0.000 & 0.024 \\
\hline Aldosterone (ng/dl) & $23.8 \pm 4.1$ & $22.5 \pm 4.4$ & $78.3 \pm 8.6^{* *}$ & $96.5 \pm 16.7 * *$ & 0.409 & 0.000 & 0.342 \\
\hline \multicolumn{8}{|l|}{ Urinary parameter } \\
\hline C-peptide (ng/mg Cr) & $0.04 \pm 0.01$ & $0.04 \pm 0.01$ & $0.30 \pm 0.04 * *$ & $0.22 \pm 0.03 * *$ & 0.149 & 0.000 & 0.186 \\
\hline Glucose (mg/mg Cr) & $0.48 \pm 0.32$ & $0.54 \pm 0.19$ & $6187 \pm 1134 * *$ & $4379 \pm 576 * *$ & 0.170 & 0.000 & 0.170 \\
\hline
\end{tabular}

Data are the means $\pm \mathrm{SE}$. Values were analyzed by $t$-test and two-way ANOVA (factorial). Cr: Creatinine. ${ }^{*} p<0.05, * * p<0.01$ compared to CT mice fed the respective diet. ${ }^{\#} p<0.05$, ${ }^{\# \#} p<0.01$ compared to the respective genotype mice fed with L-diet. Note that only HbA1c values for CT-L and CT-H were statistically analyzed. The HbA1c values for $d b$ mice are shown in italics for reference only because of the limit of measurement.

$1 \mathrm{C}, \mathrm{db}$ mice ate almost twice as much food during the experimental period as CT mice under both diet conditions. Two-way ANOVA showed that $d b$ mice had significantly higher kidney weight than CT mice. As shown in Table II, $\mathrm{H}$-diet mice, regardless of genotype, showed significantly higher kidney weight than L-diet mice. Unpaired $t$-test analysis showed that $d b-\mathrm{H}$ mice had significantly lower pancreas weight than CT-H mice. There was no significant difference in pancreas weight between $d b-\mathrm{L}$ and $d b-\mathrm{H}$ mice, whereas CT-H mice showed significantly higher pancreas weight compared to CT-L mice.

Optical coherence tomography. There was no significant effect of genotype on total retinal thickness (Table II). However, regardless of genotype, mice fed the $\mathrm{H}$-diet had significantly higher retinal thickness compared with mice fed the L-diet.

Biochemical parameters. We examined BG and UG in $d b$ and CT mice at 11 weeks of age. For BG and UG levels, $d b$ $\mathrm{L}$ and $-\mathrm{H}$ mice showed significantly higher values than $\mathrm{CT}$ $\mathrm{L}$ and $-\mathrm{H}$ mice, respectively (Table II). There was no significant difference in $\mathrm{BG}$ and $\mathrm{UG}$ levels between $d b$ or CT mice fed the different diets. For urinary C-peptide levels, $d b$ - $\mathrm{L}$ and $-\mathrm{H}$ mice showed significantly higher values than CT mice fed the same diets. There was no significant difference in urinary C-peptide levels between $d b$ or CT mice fed the different diets. For plasma insulin levels, $d b-\mathrm{H}$ mice showed significantly higher values than CT-H mice (Table II) and $d b$-H mice showed significantly higher values than $d b$-L mice. We examined HbA1c in $d b$ and CT mice at 11 weeks of age. There was a tendency of a higher HbA1c value in CT-H mice compared with CT-L mice, although it did not reach significance $(p=0.061)$. On the other hand, we were not able to accurately measure HbA1c because the values exceeded the upper limit of the test in $d b$ mice. For aldosterone levels, $d b$ - $\mathrm{L}$ and $-\mathrm{H}$ mice showed significantly higher values than CT-L and $-\mathrm{H}$ mice, respectively. There was no significant difference in aldosterone levels between $d b$ or CT mice fed the different diets.

Real-time PCR for quantification of $m R N A$. We measured mRNA levels of genes involved in the development of diabetic retinopathy. The genes Agt, Renin and Ace, belonging to the RA system and Neun, Gfap, and $C D 11 b$, expressed in the nervous system and Ager were examined (Figure 2).

There was no significant difference in Agt expression between $d b$ or CT mice fed the different diets. $d b-\mathrm{H}$ mice showed significantly lower Agt expression compared with $d b$ $\mathrm{L}$ mice. For Ace expression, $d b-\mathrm{H}$ mice showed significantly higher levels compared with CT-H mice. $d b$-H mice showed significantly higher Ace expression compared to $d b$-L mice. However, Renin was not able to be evaluated because its measurement was inconclusive (data not shown). For Ager expression, $d b-\mathrm{H}$ mice showed significantly higher values 

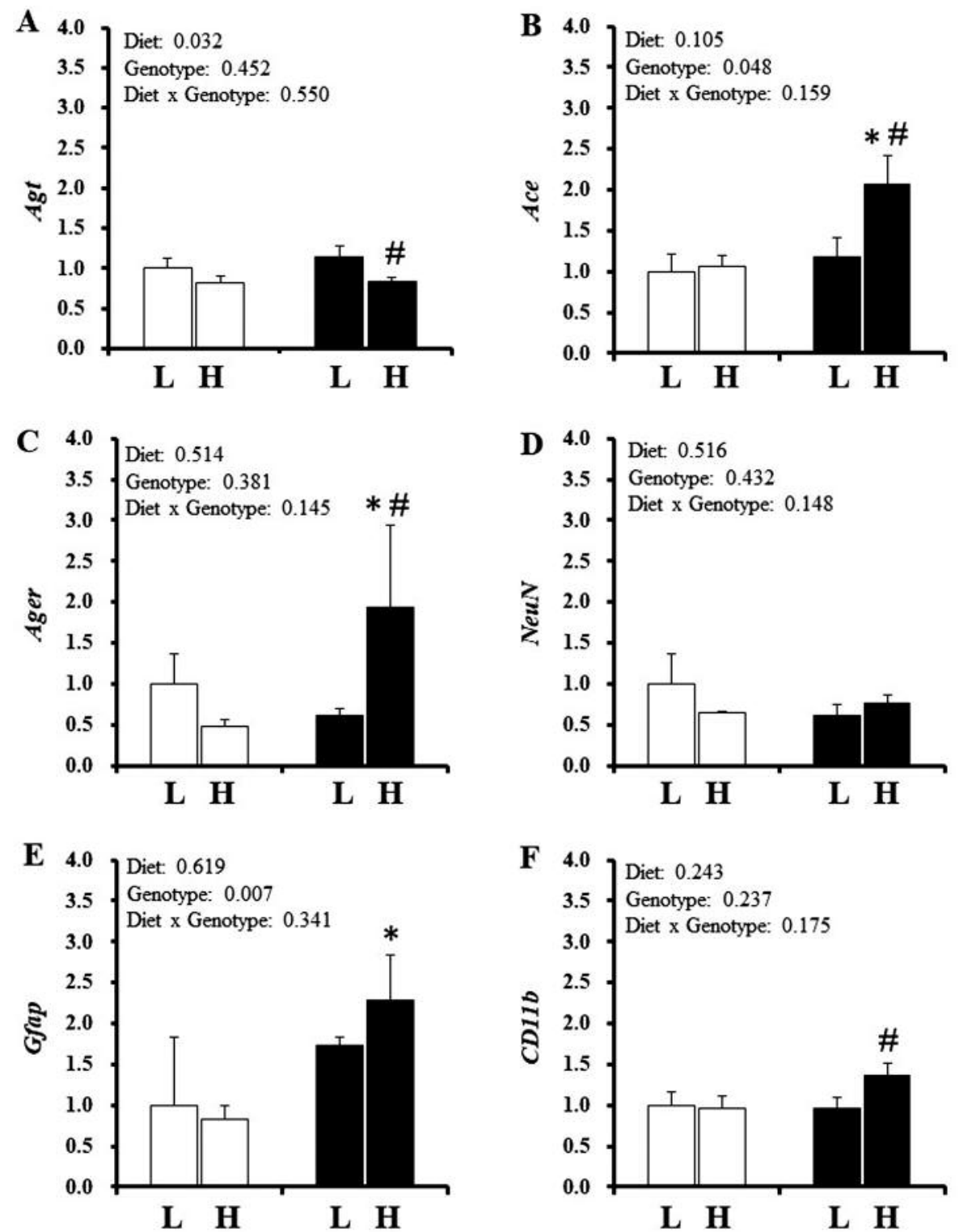

Figure 2. Messenger RNA levels of genes related to the renin-angiotensin system, diabetic conditions, and of neuronal and glial marker genes. Messenger RNA levels of Agt (A), Ace (B), Ager (C), NeuN (D), Gfap (E), and CD11b (F) in control (CT, open symbol) and db (closed symbol) mice fed with a low protein diet $(L)$ or a high protein diet $(H)$ at 11 weeks of age. The data are presented as means $+S E$ from six db and six $C T$ mice under the respective conditions. The p-values from two-way ANOVA (two factors: diet and genotype) are shown at the left and upper portion of each figure. Diet $x$ Genotype means the interaction between diet and genotype. The level of gene expression in CT-L mice was set at 1.0 using Gapdh as a reference gene. The data were analyzed statistically by the unpaired $t$-test. ${ }^{*} p<0.05$ compared with $C T$ mice fed with the respective diet. ${ }^{*} p<0.05$ compared to the same genotype mice fed the L diet.

compared with CT-H mice. Moreover, $d b$-H mice showed significantly higher Ager expression compared with $d b$-L mice.

There was no significant effect of the different diet types on Neun expression in the CT and $d b$ mice. There was no significant difference in Neun expression between $d b$ or CT mice fed the different diets.
For Gfap expression, $d b$ mice, regardless of diet, showed significantly higher levels compared with $\mathrm{CT}$ mice. $d b$-H mice showed significantly higher values than CT-H mice. There was no significant difference in Gfap expression between $d b$ or CT mice fed the different diets. Whereas there was no significant difference in CDI1b expression between CT mice fed the 
different diets, $d b-\mathrm{H}$ mice showed significantly higher $C D 11 b$ expression compared with $d b$-L mice.

\section{Discussion}

The present study revealed the impact of dietary protein and carbohydrate content on retinal manifestations in $d b$ mice, an animal model of type 2 diabetes under pair-feeding conditions (equivalent energy and fat in L- and H-diets). We showed that a high-protein low-carbohydrate diet in $d b$ mice affected retinal manifestations, including the expression of the genes, Ace, Ager, and CD11b. Additionally, mice fed a high protein diet, regardless of genotype, showed significantly higher retinal thickness values by optical coherence tomography and the lower expression of Agt.

There are many animal models with diabetic retinopathy (35). Of them, $d b$ mice are deficient in the leptin receptor and show retinopathy and nephropathy caused by type 2 diabetes (24-26). The diabetic nephropathy and glucose metabolism abnormality in $d b$ mice are aggravated by a high protein content diet $(21,22)$. In the present study, $d b$ mice were used to evaluate the effects of dietary protein and carbohydrate content on diabetic retinopathy. To evaluate the effect of dietary protein and carbohydrate, energy intake in both $d b$ and CT mice was set to be the same for both diets. Therefore, as a pair-feed experiment, the amount of food consumed by $d b$ mice fed the low protein diet was applied to $d b$ mice fed the high protein diet. In CT mice, mice fed the low or high protein diet ate similar amounts even under ad libitum conditions. As a result, $d b$ mice consumed about twice the amount of food compared with CT mice (Figure 1C). $d b$ Mice showed higher blood glucose and HbA1c levels compared with $\mathrm{CT}$ mice, regardless of diet. Over 6 weeks, $d b$ mice fed the high protein diet showed a tendency of decreased BW; therefore, we chose the experimental period to be 6 weeks. At that moment, optical coherence tomography examination did not show thinning of retinal layers in $d b$ mice, which has been reported in diabetic retinopathy (24). This means that $d b$ mice in the experimental period show the initial phase of retinal manifestations before the onset of morphological abnormality.

We initially examined gene expression in the retina of $d b$ mice fed the different diets. Alterations of gene expression in diabetic retinopathy have been reported and corresponded to proliferation of astrocytes and/or microglia (36-38). In the present study, $d b-\mathrm{H}$ and -L showed higher mRNA levels of Gfap compared with CT-H and -L, respectively. This finding indicates that higher Gfap expression may correspond to the diabetic condition, but that it is not greatly influenced by the different protein and carbohydrate content diets, even in $d b$ mice. Although morphological change was not apparent, the higher expression of Gfap (as a retinal astrocyte marker) under diabetic conditions is consistent with previous reports (36-38). Moreover, $d b$-H showed significantly higher levels of $C D 11 b$ mRNA, a microglial marker, than $d b$-L, suggesting that a higher dietary protein content may influence the proliferation of microglia. On the other hand, NeuN, a neuronal cell marker, was similar in $d b$ and CT mice fed either diet. In addition, genes related to the RA system were examined because RA system inhibitors can protect against diabetic retinopathy (13-17); however, results were somewhat complicated. For the high protein diet, Agt mRNA levels were significantly lower compared with low protein diet conditions. On the other hand, levels of Ace mRNA were significantly higher in $d b$ - $\mathrm{H}$ than $d b$-L mice. Up- or downregulation of RA system activity does not have to result from alterations in mRNA levels only; the level of protein and activity in the RA system should also be examined. However, inhibitors of the RA system are effective against diabetic retinopathy (13-17). RA system inhibitors can act through inhibition of ligand production or inhibition of receptor action. The expression of Ace is likely to contribute to Ace protein levels, which may inhibit the RA system. Ager mRNA levels are higher in $d b$ - $\mathrm{H}$ mice than $d b$ - $\mathrm{L}$ mice, suggesting that glycated proteins resulting from higher blood glucose may enhance signaling through induction of AGER protein expression. Under diabetic conditions, expression of $C D 11 b$, Ace, and Ager in the retina was upregulated by different dietary protein and carbohydrate contents, whereas Agt expression was downregulated in high protein diet conditions regardless of genotypes. $d b$ Mice under the different dietary conditions showed similar blood glucose and $\mathrm{HbA} 1 \mathrm{c}$ levels, indicating that alterations in the expression of the above genes may not be explained by higher blood glucose alone. An endocrinological change may have resulted from the different protein content and may involve glucagon and vasopressin (39).

Specific nutritional intervention for diabetic retinopathy has not been performed; however, restriction of dietary protein intake has been performed for diabetic nephropathy $(10,11)$. Nutritional-based approaches have a high potential to be developed as adjunct intervention for the occurrence or progression of diabetic retinopathy in the initial stages. Nutritional intervention can serve as a non-invasive and costeffective treatment (40). As a general nutritional intervention for diabetic retinopathy, to prevent increased blood glucose and blood pressure, restriction of energy intake and salt intake has been considered (40). For Japanese food, a restriction of energy intake, for example by decreased intake of the staple food rice, may lead to a higher protein intake. In the present study, the proportion of protein and carbohydrate in a diet influenced retinal manifestations in control and diabetic mice, such as retinal thickness and gene expression. Further examination is necessary to explain the pathophysiological consequences of the gene expression altered by the diets. However, the present study was informative for considering specific nutritional intervention of diabetic retinopathy. 


\section{Acknowledgements}

This work was supported by grants from the Ministry of Education, Culture, Sports, Science, and Technology in Japan (\#25350873 to E. A.) and by the Kodama Memorial Fund for Medical Research. The Authors thank the Joint Research Laboratory, Kagoshima University Graduate School of Medical and Dental Sciences for the use of its facilities. The Authors would also like to thank Edanz Group Ltd. for editing the manuscript.

\section{References}

1 Song MK, Roufogalis BD and Huang TH: Modulation of diabetic retinopathy pathophysiology by natural medicines through PPAR- $\gamma$-related pharmacology. Br J Pharmacol 165: 419, 2012.

2 Yau JW, Rogers SL, Kawasaki R, Lamoureux EL, Kowalski JW and Bek T: Global prevalence and major risk factors of diabetic retinopathy. Diabetic Care 35: 556-564, 2012.

3 Cruickshanks KJ, Ritter LL, Klein R and Moss SE: The association of microalbuminuria with diabetic retinopathy: The Wisconsin Epidemiologic Study of Diabetic Retinopathy. Ophthalmology 100: 862-867, 1993.

4 Zimmet P, Alberti KG and Shaw J: Global and societal implications of the diabetes epidemic. Nature 414: 782-787, 2001.

5 Sone H, Katagiri A, Ishibashi S, Abe R, Saito Y, Murase T, Yamashita H, Yajima Y, Ito H, Ohashi Y, Akanuma Y, Yamada $\mathrm{N}$ and JD Study Group: Effects of lifestyle modifications on patients with type 2 diabetes: the Japan Diabetes Complications Study (JDCS) study design, baseline analysis and three yearinterim report. Horm Metab Res 34: 509-515, 2002.

6 Magkos F, Yannakoulia M, Chan JL and Mantzoros CS: Management of the metabolic syndrome and type 2 diabetes through lifestyle modification. Annu Rev Nutr 29: 223-256, 2009.

7 Inadera $\mathrm{H}$ : Developmental origins of obesity and type 2 diabetes: molecular aspects and role of chemicals. Environ Health Prev Med 18: 185-197, 2013.

8 Tsunehara CH, Leonetti DL and Fujimoto WY: Diet of secondgeneration Japanese-American men with and without noninsulin-dependent diabetes. Am J Clin Nutr 52: 731-738, 1990.

9 Nanri A, Mizoue T, Noda M, Takahashi Y, Kato M, Inoue M, Tsugane S and Japan Public Health Center-based Prospective Study Group: Rice intake and type 2 diabetes in Japanese men and women: the Japan public health center-based prospective study. Am J Clin Nutr 92: 1468-1477, 2010.

10 Layman DK, Clifton P, Gannon MC, Krauss RM and Nuttall FQ: Protein in optimal health: heart disease and type 2 diabetes. Am J Clin Nutr 87: 1571S-1575S, 2008.

11 Pan Y, Guo LL and Jin HM: Low-protein diet for diabetic nephropathy: A meta-analysis of randomized controlled trials. Am J Clin Nutr 88: 660-666, 2008.

12 Rietman A, Schwarz J, Tomé D, Kok FJ and Mensink M: High dietary protein intake, reducing or eliciting insulin resistance? Eur J Clin Nutr 68: 973-979, 2014.

13 Chaturvedi N, Sjølie AK, Stephenson JM, Abrahamian H, Keipes M, Castellarin A, Rogulja-Pepeonik Z and the EUCLID Study Group: Effect of lisinopril on progression of retinopathy in normotensive people with type 1 diabetes. Lancet 351: 28-31, 1998.
14 Chaturvedi N, Porta M, Klein R, Orchard T, Fuller J, Parving $\mathrm{HH}$, Bilous R, Sjølie AK and the DIRECT Programme Study Group: Effect of candesartan on prevention (DIRECT-Prevent 1) and progression (DIRECT-Protect 1) of retinopathy in type 1 diabetes: randomized, placebo-controlled trials. Lancet 372 : 1394-1402, 2008.

15 Sjølie AK, Klein R, Porta M, Orchard T, Fuller J, Parving HH, Bilous R, Chaturvedi N and the DIRECT Study Group: Effect of candesartan on progression and regression of retinopathy in type 2 diabetes (DIRECT-Protect 2): a randomized placebocontrolled trial. Lancet 372: 1385-1393, 2008.

16 Mauer M, Zinman B, Gardiner R, Suissa S, Sinaiko A, Strand T, Drummond K, Donnelly S, Goodyer P, Gubler MC and Klein R: Renal and retinal effects of enalapril and losartan in type 1 diabetes. N Engl J Med 361: 40-51, 2009.

17 Harindhanavudhi T, Mauer M, Klein R, Zinman B, Sinaiko A, Caramori ML and the RASS group: Benefits of ReninAngiotensin blockade on retinopathy in type 1 diabetes vary with glycemic control. Diabetes Care 34: 1838-1842, 2011.

18 Peters H, Border WA and Noble NA: Angiotensin II blockade and low-protein diet produce additive therapeutic effects in experimental glomerulonephritis. Kidney Int 57: 1493-1501, 2000.

19 Shafrir E, Ziv E and Mosthaf L: Nutritionally induced insulin resistance and receptor defect leading to beta-cell failure in animal models. Ann NY Acad Sci 892: 223-246, 1999.

20 Davis RC, Castellani LW, Hosseini M, Ben-Zeev O, Mao HZ, Weinstein MM, Jung DY, Jun JY, Kim JK, Lusis AJ and Péterfy M: Early hepatic insulin resistance precedes the onset of diabetes in obese C57BLKS- $d b / d b$ mice. Diabetes 59: 1616-1625, 2010.

21 Arimura E, Horiuchi M, Kawaguchi H, Miyoshi N, Aoyama K and Takeuchi T: Low-protein diet improves blood and urinary glucose levels and renal manifestations of diabetes in C57BLKS$d b / d b$ mice. Eur J Nutr 52: 813-824, 2013.

22 Arimura E, Pulong WP, Marchianti ACN, Nakakuma M, Abe M, Ushikai $\mathrm{M}$ and Hroiuchi $\mathrm{M}$ : Deteriorated glucose metabolism with a high-protein, low-carbohydrate diet in $d b$ mice, an animal model of type 2 diabetes, might be caused by insufficient insulin secretion. Eur J Nutr 56: 237-246, 2017.

23 Roy MS, Stables G, Collier B, Roy A and Bou E: Nutritional factors in diabetics with and without retinopathy. Am J Clin Nutr 50: 728-730, 1989.

24 Yang Q, Xu Y, Xie P, Cheng H, Song Q, Su T, Yuan S and Liu Q: Retinal neurodegeneration in $d b / d b$ mice at the early period of diabetes. J Ophthalmol 757412, 2015.

25 Chen H, Charlat O, Tartaglia LA, Woolf EA, Weng X, Ellis SJ, Lakey ND, Culpepper J, More KJ, Breitbart RE, Duyk GM, Tepper RI and Morgenstern JP: Evidence that the diabetes gene encodes the leptin receptor: identification of a mutation in the leptin receptor gene in $d b / d b$ mice. Cell 84: 491-495, 1996.

26 Sharma K, McCue P and Dunn SR: Diabetic kidney disease in the db/db mouse. Am J Physiol Renal Physiol 284: F1138-F1144, 2003.

27 Matsumoto M, Tanimoto M, Gohda T, Aoki T, Murakoshi M, Yamada K, Yamazaki T, Kaneko S, Horikoshi S and Tomino Y: Effect of pitavastatin on type 2 diabetes mellitus nephropathy in KK-Ay/Ta mice. Metabolism 57: 691-697, 2008.

28 Maezawa Y, Yokote K, Sonezaki K, Fujimoto M, Kobayashi K, Kawamura H, Tokuyama T, Takemoto M, Ueda S, Kuwaki T, Mori S, Wahren J and Saito Y: Influence of C-peptide on early glomerular changes in diabetic mice. Diabetes Metab Res Rev 22: 313-322, 2006. 
29 Reich HN, Oudit GY, Penninger JM, Scholey JW and Herzenberg AM: Decreased glomerular and tubular expression of ACE2 in patients with type 2 diabetes and kidney disease. Kidney Int 74: 1610-1616, 2008.

30 Juárez P, Vilchis-Landeros MM, Ponce-Coria J, Mendoza V, Hernández-Pando R, Bobadilla NA, and López-Casillas F: Soluble betaglycan reduces renal damage progression in $d b / d b$ mice. Am J Physiol Renal Physiol 292: F321-F329, 2007.

31 Wang HY, Hsieh PF, Huang DF, Chin PS, Chou CH, Tung CC, Chen SY, Lee LJ, Gau SSF and Huang HS: RBFOX3/NeuN is required for hippocampal circuit balance and function. Sci Rep 5: 17383, 2015.

32 Rusnakova V, Honsa P, Dzamba D, Ståhlberg A, Kubista M and Anderova M: Heterogeneity of astrocytes: from development to injury - single cell gene expression. PloS ONE 8: e69734, 2013.

33 Wu X, He Y, Hsuchou H, Kastin AJ, Rood JC and Pan W: Essential role of interleukin-15 receptor in normal anxiety behavior. Brain Behav Immun 24: 1340-1346, 2010.

34 Motyl KJ, Raetz M, Tekalur SA, Schwartz RC and McCabe LR: CCAAT/enhancer binding protein $\beta$-deficiency enhances type 1 diabetic bone phenotype by increasing marrow adiposity and bone resorption. Am J Physiol Regul Integr Comp Physiol 300: R1250-R1260, 2011.

35 Mi XS, Yuan TF, Ding Y, Zhong JX and So KF: Choosing preclinical study models of diabetic retinopathy: key problems for consideration. Drug Des Devel Ther 18: 2311-2319, 2014.
36 Bek T: Immunohistochemical characterization of retinal glial cell changes in areas of vascular occlusion secondary to diabetic retinopathy. Acta Ohthalmol Scand 75: 388-392, 1997.

37 Li Q, Zemel E, Miller B and Perlman I: Early retinal damage in experimental diabetes: electroretinographical and morphological observations. Exp Eye Res 74: 615-625, 2002.

38 Arroba AI, Alcalde-Estevez E, García-Ramírez M, Cazzoni D, de la Villa P, Sánchez-Fernández EM, Mellet CO, Fernández JMG, Hernández C, Simó R and Valverde ÁM: Modulation of microglia polarization dynamics during diabetic retinopathy in $d b / d b$ mice. Biochim Biophys Acta 1862: 1663-1674, 2016.

39 Bankir L, Roussel R and Bouby N: Protein- and diabetes-induced glomerular hyperfiltration: role of glucagon, vasopressin, and urea. Am J Physiol Renal Physiol 309: F2-F23, 2015.

40 Sharma Y, Saxena S, Mishra A, Saxena A and Natu SM: Nutrition for diabetic retinopathy: plummeting the inevitable threat of diabetic vision loss. Eur J Nutr 56: 2013-2027, 2017.

Received November 29, 2017

Revised December 19, 2017

Accepted December 20, 2017 